\title{
Analysis of Internet Marketing Development and Innovative Path
}

\author{
Wei Liu \\ School of business, Chengdu University of Technology, Chengdu Sichuan, 610059, China
}

Keywords: Internet marketing, Development, Innovation, Path.

\begin{abstract}
As the era of data comes, economic trading communication mode cannot be limited to face-to-face transaction. Internet marketing structure starts to be established. In actual project operation process, relevant operation personnel can achieve transformation of whole project marketing structure and really establish the operation mode which adapts era development only when they master basic mode and basic advantage of internet marketing and conduct effective publicity method. This paper simply analyzes development history of internet marketing, discusses the advantages and disadvantages of internet marketing and intensively explains innovation breakthrough path, in the hope of bettering helping relevant enterprises and merchants to carry out optimized internet marketing and achieve diversified development of market structure.
\end{abstract}

\section{Introduction}

For internet marketing, overall structure can be optimized smoothly only when the relationship between customers and traders are optimally established. In 1996, Chinese merchants started to try book selling on network, which opened the whole internet marketing era. One year later, complete network marketing and trade operation appeared in Shandong, China. A peasant set up Wanhong Flowers and Plants Company, achieved networked flowers and plants marketing structure, even extended the business abroad and realized smooth promotion of overall internet marketing structure. China’s internet marketing mode gradually occupied China's trade market.

\section{Development history of internet marketing}

Compared with the development of international Internet of Things, China's internet marketing project develops late. Technical application, masses' acceptance level and use effect fall behind. China's internet marketing mainly includes seeding period, germination period and application period of internet marketing project.

\section{Seeding period of internet marketing project.}

Seeding period of internet marketing project was before 1997 when internet technology was not very popular in China. China's internet was opened in mid-1994. corresponding marketing form gradually entered Chinese market, and relevant enterprises gradually realized internet marketing project. But, the overall project structure and basic technology were in the rudiment period. Many merchants did not accept it very much, and they were not clear about basic marketing structure, basic idea and measures. Thus, few enterprises used internet marketing mode to promote products. The whole internet marketing market was very sluggish ${ }^{[1]}$. In addition, many merchants misunderstood internet marketing mode, excessively exaggerated actual effect and function of marketing measures and generated wrong deconstruction of the overall structure. Thus, in this period, corresponding internet marketing failed to achieve substantial progress, and the overall market structure failed to get further development and establishment. Nevertheless, people had cognition foundation for internet marketing structure and concept and formed the seeding period of technical development.

\section{Germination period of internet marketing project.}

Till 1997, internet marketing project in Mainland China started to attract corresponding merchants. China Network Information Centre issued a very critical report on China's internet development conditions and actual data analysis. The report marked that internet users in China had exceeded 600000 till 1997, and there were more than 1500 websites. For that era, this figure can explain the features and trend of era development. The overall internet marketing entered the 
germination period. The number of basic network service domain name registrations and search engines was on the rise. For merchants, it had great commercial value. They could deeply mine trade market. Relevant merchants started to realize the advantages of internet marketing project. Overall internet marketing started to enter the development trend. Thus, the overall structure became continuously complete and rich ${ }^{[2]}$.

\section{Development and application period of internet marketing project.}

In 2001, China's internet marketing had thoroughly entered high-speed development period, and overall project technology became gradually complete. For merchants and users, internet marketing was no longer a simple concept, but a sign which could be transformed to interest. Online marketing process was being enhanced continuously, and the overall structure became increasingly perfect. People started to set up stores online, and internet marketing was dominated by online stores. This period is mature period of network economy development and also the progress period of overall development pace. This period plays a significant role for China's economy and drives per-capita GDP of China to some extent.

In recent years, internet marketing has developed and its level has kept improving. Corresponding technology and projects become gradually diversified, population base of China is important driving force of internet marketing development. Relevant operation can make enterprises gain the maximum profits and offer the greatest conveniences for consumers. Internet marketing mode really serves for people. When corresponding project is in the operation process, there are corresponding project advantages and problems.

\section{Project advantages and disadvantages of internet marketing}

\section{Project advantages of internet marketing project.}

1) Beneficial for enterprises to ensure basic cost advantage

In the operation process of internet marketing mode, enterprise marketing personnel just need to carry out intensive project publicity on network. Then release of product information can guarantee registration and delivery in the first time. Consumers can directly view and receive corresponding product introduction and information, which not just effectively reduces middle distribution link, but also effectively improves project operation time and really achieves free acquisition of product information. As long as consumers have specific requirements, intensive collection and organization can be conducted through corresponding information, and then corresponding purchase behavior is carried out. For merchants, this can ensure optimal cost control to some extent and really achieves overall cost reduction. Intensive project introduction is only made for potential customers, and corresponding trade relation is established ${ }^{[3]}$. Moreover, in the operation process of internet marketing, most customers browsing are potential customers. Relevant marketing personnel should carry out intensive project introduction, guarantee accuracy of targeting audience, evade useless information transmission, ensure complete operation of overall structure, achieve optimal operation of basic project and direct product sale. Since internet marketing does not need to buy physical stores, this is the maximum cost reduction for small merchants. This really enhances reduction of operation cost.

2) Beneficial for enterprises to establish interactive communication with customers

In practical operation process of internet marketing, corresponding merchants should establish interaction and communication with customers in order to carry out intensive project marketing. In internet marketing, merchants can intensively gather customers' opinions and guarantee one-to-one service. To some extent, this improves overall service quality and communication frequency, and guarantees optimal communication between customers and merchants. Furthermore, some merchants require customers to participate in design, research and development. The mode that products focus on customers is really realized. In actual marketing process, corresponding professional personnel will be allocated to intensively answer questions and introduce product information in an all-round way. This achieves humanization and individuation of communication structure and helps to increase product sales volume to some extent. 


\section{3) Beneficial to upgrade and optimize basic publicity mode}

In practical project publicity process, the completeness of overall operation structure is achieved. Relevant merchants not just establish fundamental marketing websites, but also set up complete user database. Besides, they intensively gather data about region, age, hobbies and gender, and can push advertisement for corresponding group and track advertisement browsing effect so as to achieve the optimal output of publicity effect. On this basis, they can accurately judge the consumption of customers. Meanwhile, consumers can make a choice while browsing products and make purchase decision through information collection.

\section{4) Beneficial for consumers to make independent consumption choice}

For merchants, internet marketing is an important guarantee. For customers, it also has great advantages. It is a new consumption experience. In data era, fundamental information collection is not limited to TV and newspaper. People can gain more information via network. As advertisements are filled in life, it is very troublesome for customers to carry out effective screening. In internet marketing structure, customers can save much time. They just need to make targeted search according to their needs. The operation of overall consumption process can be achieved through corresponding operation and information retrieval, without consideration of time and regional restrictions. This ensures timeliness of information browsing. Besides, customers need to face enthusiastic sales personnel, but just need to make independent choices. They can buy products through a computer. Flexible and convenient consumption trend is gradually favored by consumers, which also ensures development of internet marketing ${ }^{[4]}$.

\section{Project disadvantages of internet marketing.}

Any new project will have advantages and disadvantages. Internet marketing is of no exception. Firstly, in the operation process of fundamental project, the sense of trust may be deficient. Since traditional trading behavior is based on face-to-face, people pay attention to product examination on the site. Thus, many consumers scorn internet marketing. They worry the product does not comply with the product information. Some people will make a decision according to the comments. Hence, optimization of internet marketing can be ensured only when basic quality is guaranteed. Secondly, fundamental price. In actual marketing process, consumers can vividly know corresponding product price. For consumers, this brings convenience. But for merchants, if all prices are transparent, price competition will be caused. Some will result in the decrease in merchants' profit, and even lead to failure. This is not beneficial to positive market development. Additionally, in internet marketing mode, the price is the selling price and cannot be bargained. This will result in unnecessary delay of business opportunity and generate adverse effect on market construction. Thirdly, fundamental security. For basic consumption process, structure optimization of the overall project can be achieved only when basic quality and consumption structure are guaranteed. However, with continuous development of economy and technology, many phishing websites appear in internet marketing. This gives rise to unsecure influence on the overall mode. Once some consumers enter phishing websites, consumption items cannot be established, and huge economic losses will be caused. Thus, the overall operation mode generate bad social influence. With regard to the hidden danger of payment link, relevant operating personnel should give necessary attention. Finally, the limitation of basic consumption group. Although network has developed to certain degree, for the applicable group of basic network, there is certain limitation. They are mainly people at the age below 40 . The old people are not proficient in computer operation, which results in certain limitation of overall group.

\section{Innovation and breakthrough of internet marketing}

For the operation of internet marketing mode, further operation of fundamental project can be guaranteed only when optimization of overall structure is achieved. Relevant management and operating personnel should optimize and upgrade the project according to actual conditions so as to further achieve innovation and breakthrough of basic mode. For internet marketing, experience marketing and interactive participation are the major paths of internet marketing. Only when the two points are achieved can overall marketing mode be upgraded smoothly. It is required to focus on project innovation and breakthrough in actual operation process and establish the optimal buying 
inclination through consumers' personal experience. Moreover, project research personnel should establish and improve overall transaction structure in accordance with internet marketing advantages, make sure the rights and interests of consumers and merchants are effectively satisfied, and establish more complete interaction communication ${ }^{[5]}$.

\section{Conclusion}

In one word, internet marketing mode is continuously established and develops. Corresponding e-commercial merchants should further give play to corresponding project advantages, guarantee to correct problems and really contribute to sustainable development of internet marketing market.

\section{References}

[1] Shan Qianzhi, Analysis of value expansion of integrated marketing communication theory in internet era - case study of internet marketing in contemporary China's film market, Consume Guide, 2015,17(08):74-74.

[2] Lv Xingguang, Development and innovation of internet marketing in China, Money China, 2013,17(34):27-29.

[3] Li Junzhao, Internet thinking of news marketing, Chinese Journalist, 2016,14(02):73-75.

[4] Lu Yuhui, Survival and evolution: internet prospect of Chinese film marketing, New Films, 2015,17(06):73-78.

[5] Chen Lin, Teaching research on internet marketing under big data background, Western China Quality Education, 2015,1(10):85-85. 